\title{
Pediatric scaphoid nonunion treated with iliac wing bone graft and screw fixation: Two case reports
}

\author{
Alper Çıraklı ${ }^{\text {* }}$, Ahmet Pişkinª, Sevgi Çıraklı ${ }^{\mathrm{b}}$, Ali Varlıa ${ }^{\mathrm{a}}$, Birol Gülman ${ }^{\mathrm{a}}$ \\ ${ }^{a}$ Department of Orthopedics and Traumatology, Faculty of Medicine, Ondokuz Mayls University, Samsun, Turkey \\ ${ }^{b}$ Department of Pediatrics, Faculty of Medicine, Ondokuz Mayı University, Samsun, Turkey
}

ARTICLE INFO ABSTRACT

Article History

Received $29 / 05 / 2013$

Accepted 24/06/2013

\section{* Correspondence to:}

Alper Çıraklı

Department of Orthopedics and

Traumatology,

Faculty of Medicine,

Ondokuz Mayıs University,

Samsun, Turkey

e-mail: alperomu@gmail.com
Scaphoid fractures are rarely seen in the pediatric age group. If the fracture is diagnosed late or appropriate treatment is not applied, it may result in nonunion. Wrist pain and restricted movements in these school age cases lead to problems in the developmental activites of the children. Therefore, with the aim of a speedy return to activity, the two pediatric cases presented here were treated with iliac wing bone graft and screw fixation and the results were successful in conformity with literature. As these fractures are rarely seen, it was aimed to evaluate these cases with the relevant literature.

J. Exp. Clin.Med., 2013; 30: 261-263

\section{Keywords:}

Nonunion

Pediatric

Scaphoid

Surgical treatment

\section{Introduction}

Scaphoid fractures are rarely seen in the pediatric age group and comprise $0.4 \%$ of all pediatric fractures, $0.45 \%$ of upper extremity fractures and $2.9 \%$ of wrist fractures (Christodoulou and Colton, 1986; Wulff and Schmidt, 1998). The majority of these fractures are treated successfully with standard plaster cast immobilisation and nonunion rates are very low at $0.8 \%$ (Fabre et al., 2001). However, if diagnosis is not made at the first examination or the proper treatment is not applied, the fracture may result in nonunion. This paper presents an evaluation of the treatment and results of two pediatric cases who attended to our clinic with complaints of pain because of scaphoid nonunion, which is a rarely seen event.

\section{Cases}

Two pediatric cases, one female and one male, aged 14 and 15 years, were evaluated with a localisation of scaphoid midsection. The fracture mechanism was determined as that the girl had struck a ball with her hand nine months ago and the boy had fallen on his hand while playing football eight months ago. Both cases had received analgesic therapy at the centres where they had presented following the trauma. As the pain had not receded, the cases were referred to our clinic with a diagnosis of scaphoid nonunion.

In the physical examination, both cases had pain in the scaphoid area on palpation and the wrist movements were painful and restricted. In the radiographic examination, there was an appearance consistent with nonunion (Herbert-Fisher Classification D2) in the scaphoid midsection in both cases (Fig. 1) (Tomak et al., 1999). After taking informed consent from patients and their families, treatment was applied of iliac wing bone graft and Acutrac screw fixation with using volar exposure. The mean union time was eight weeks. Three months follow up period, both patients continue to be healthy and continue with their school education with good wrist joint functions. No complications developed in the postoperative period, clinical and radiological successful results were obtained (Fig. 2). 


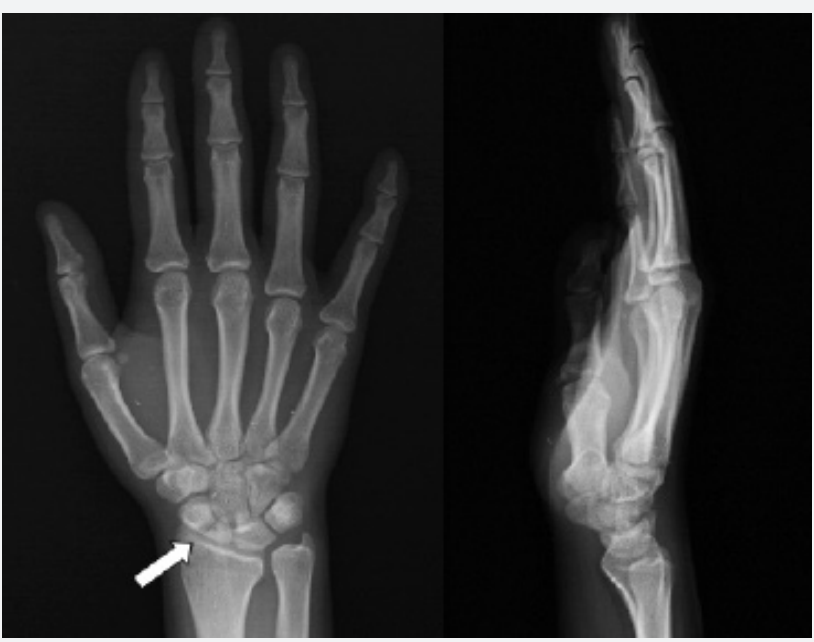

Fig. 1. The nonunion line seen on the preoperative direct radiographs of the female case

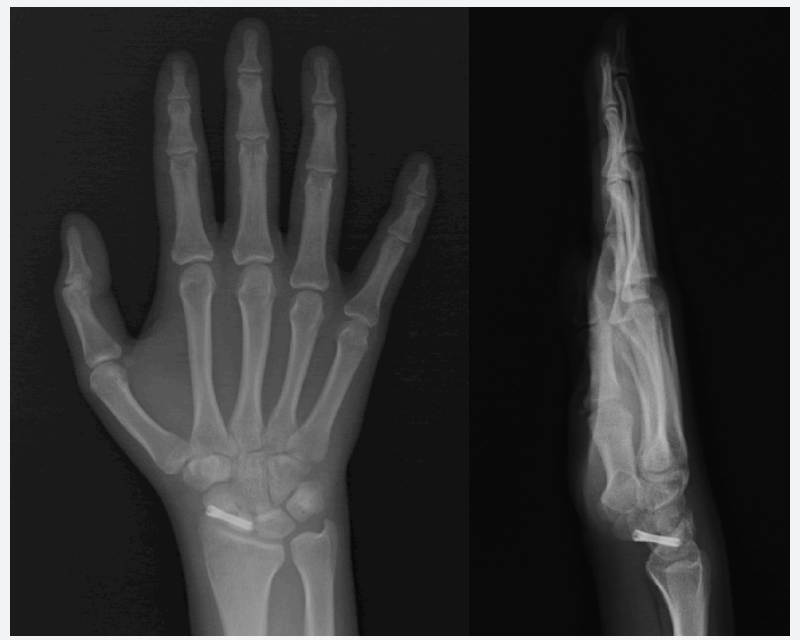

Fig. 2. Recovery of the nonunion line seen on the direct radiographs of the female case at follow-up period

\section{Discussion}

Scaphoid fractures are rarely seen in the pediatric age group and comprise $0.4 \%$ of all pediatric fractures, $0.45 \%$ of upper extremity fractures and $2.9 \%$ of wrist fractures (Christodoulou and Colton, 1986; Wulff and Schmidt, 1998). They are most frequently seen between the ages of 12-15 years (Toh et al., 2003). Unlike in adults, pediatric scaphoid fractures are observed at rates of 59\%-87\% in the distal zone, $12 \%-36 \%$ in the midsection and 0\%-2\% in the proximal zone (Wulff and Schmidt, 1998).

The subject of scaphoid nonunion has recently become an issue of interest in the surgical treatments of pediatric patients. The majority of these fractures are treated successfully with standard plaster cast immobilisation and nonunion rates are very low at $0.8 \%$ (Fabre et al., 2001). The healing capacity of the scaphoid in children is better than that of adults but if good treatment is not applied, nonunion may result (Hamdi and Khelifi, 2011).

In the literature, Maxted and Owen (1982) reported two cases, Wilson-MacDonald (1987) one case, Onuba and Ireland (1983) two cases and Southcott and Rosman (1977) eight cases. In wider series reported by Chloros et al. (2007), $100 \%$ union and excellent results were obtained from 12 cases treated with iliac wing bone graft and screw fixation. Henderson and Letts (2003) and Mintzer and Waters (1999) also reported graft and screw fixation was successful and complication free. However, there have been concerns that the use of a screw may negatively affect the growth of the scaphoid (Toh et al., 2003). Although there have not been a sufficient number of studies published, the use of screws after the age of 11 years has been reported to be safe (Toh et al., 2003). Just as in adults, in selected pediatric cases with fibrous nonunion, it has been reported that percutaneous screw fixation can be used (Jeon et al., 2008). In the two pediatric cases presented here, aged 14 and 15 years old, the fractures localised in the midsection were treated with iliac wing bone graft and screw fixation. Successful results were obtained and no complications were observed which was conformity with literature.

Generally scaphoid fractures are not diagnosed from the first radiographs in up to $25 \%$ of cases, in other word, the fracture is missed. In this respect, particularly in pediatric cases, a fracture which would be able to be treated with plaster cast immobilisation will have to be treated with surgical methods. In these cases during the development period of children, developmental problems arise. Therefore, by accepting suspect cases as if there were a fracture, monitoring can be considered necessary. It can be concluded that treatment with iliac wing bone graft and screw fixation can be used as successful treatment in cases who develop nonunion.

\section{REFERENCES}

Chloros, G.D., Themistocleous, G.S., Wiesler, E.R., 2007. Pediatric scaphoid nonunions. J. Hand. Surg. Am. 32, 172-176.

Christodoulou, A.G., Colton, C.L., 1986. Scaphoid fractures in children. J. Pediatr. Orthop. 6, 37-39.

Fabre, O., De Boeck H., Haentjens, P., 2001. Fractures and nonunions of the carpal scaphoid in children. Acta Orthop. Belg. 67, 121-125.

Hamdi, M.F., Khelifi, A., 2011. Operative management of nonunion scaphoid fracture in children: A case report and literature review. Musculoskelet Surg. 95, 49-52.

Henderson, B., Letts M., 2003. Operative management of pediatric scaphoid fracture nonunion. J. Pediatr. Orthop. $23,402-426$.

Jeon, I.H., Kochhar, H., Lee B.W., Kim S.Y., Kim, P.T., 2008. Percutaneous screw fixation for scaphoid nonunion in skeletally immature patients: A Report of two cases. J. Hand. Surg. 33, 656-659.

Maxted, M.J., Owen, R., 1982. Two cases of nonunion of carpal scaphoid fractures in children. Injury. 13, 441-443.

Mintzer, C.M., Waters P.M., 1999. Surgical treatment of pediatric scaphoid fracture nonunions. J. Pediatr. Orthop. 19, $236-239$.

Onuba, O., Ireland, J., 1983. Two cases of non-union of fractures of the scaphoid in children. Injury. 15, 109-112.

Southcott, R., Rosman, M.A., 1977. Nonunion of carpal scaphoid fractures in children. J. Bone Joint Surg. Br. 59, 20-23.

Toh, S., Miura H., Arai, K., Yasumura, M., Wada, M., Tsubo, K., 2003. Scaphoid fractures in children: problems and treatment. J. Pediatr. Orthop. 23, 216-221. 
Tomak, Y., Karaismailoğlu, N.K., Tilki, K., Diri B., Dabak, N., Andaç, A., 1999. Skafoid nonunionlarının iliak kemik grefti ve herbert vida fiksasyonu ile tedavisi. O.M.Ü Tıp Dergisi. 16, 7-18.

Wilson-MacDonald, J., 1987. Delayed union of the distal scaphoid in a child. J. Hand. Surg. Am. 12, 520-522.

Wulff, R.N., Schmidt, T.L., 1998. Carpal fractures in children. J. Pediatr. Orthop. 18, 462-465. 